\title{
Revision of the genera Anisarthrocera, Rhampholyssa and Rhampholyssodes, description of the new genus Somalarthrocera and a phylogenetic study of the tribe Cerocomini (Coleoptera: Meloidae)
}

\author{
Federica TURCO and Marco A. BOLOGNA \\ Dipartimento di Biologia, Università degli Studi "Roma Tre", Viale Marconi 446, 00146 Roma, Italy; \\ e-mails: federicaturco@yahoo.it, bologna@uniroma3.it
}

Key words. Meloidae, blister beetles, Cerocomini, Anisarthrocera, Rhampholyssa, Rhampholyssodes, Somalarthrocera, taxonomy, new genus, new species, phylogeny, bionomics, faunistics, biogeography

\begin{abstract}
Four genera of the blister beetle tribe Cerocomini are revised, including the new genus Somalarthrocera. The genera Rhampholyssa Kraatz, 1863 and Somalarthrocera comprise two species each, whereas Anisarthrocera Semenow, 1895 and Rhampholyssodes Kaszab, 1983 are monotypic. S. savanicola sp. n. from Kenya is described, S. semirufa (Fairmaire, 1882) comb. n. is proposed, as well as new synonymy: A. batesi (Marseul, 1872) = A. batesi villiersi Kaszab, 1968. Phylogenetic relationships among the six genera of the tribe are defined by a cladistic analysis, which indicates three clades, one basal, represented by the genus Cerocoma Geoffroy, 1762, the second including Anisarthrocera and the pair Rhampholyssa and Rhampholyssodes, and the third including Diaphorocera Heyden, 1863 and Somalarthrocera. Bionomical information available for the four revised genera is summarised. Keys to these genera and to the species of the two non-monotypic genera are presented, as well as diagnoses of genera and species and catalogue of localities. Anisarthrocera is distributed in the northern Persian Gulf, Rhampholyssa in the Turanian depression, Rhampholyssodes is endemic to the eastern Arabian Peninsula, and Somalarthrocera is distributed in Somalia and Kenya. A brief biogeographical analysis of this primarily Palaearctic tribe is also presented.
\end{abstract}

\section{INTRODUCTION}

Meloidae is a family of Coleoptera Tenebrionoidea, popularly named blister beetles, characterised by cantharidin production and hypermetamorphic development, except possibly in the primitive subfamily Eleticinae as inferred from larval morphology (Pinto et al., 1996; Bologna et al., 2001). Larvae feed on eggs, provisions and larvae of Hymenoptera Apoidea, or on grasshopper eggs (Acridoidea) (Bologna, 1991), and the first instar of several groups may have some phoretic adaptations; the biology of representatives of Eleticinae is still unknown. Recently this family was revised using a cladistic perspective (Bologna \& Pinto, 2001) and four subfamilies recognised: Eleticinae, Meloinae, Tetraonycinae and Nemognathinae (Pinto \& Bologna, 1999; Bologna \& Pinto, 2002).

Recently our attention has focused on the revision of the Old World tribe Cerocomini, comprising some 40 species, which belongs to the subfamily Meloinae and includes five described genera (Bologna \& Pinto, 2002): Cerocoma Geoffroy, 1762, Diaphorocera Heyden, 1863, Anisarthrocera Semenow, 1895, Rhampholyssa Kraatz, 1863 and Rhampholyssodes Kaszab, 1983. A new genus Somalarthrocera is described in the present paper. The monophyly of the tribe is strongly supported by adult synapomorphies, such as the position of the antennae, placed far from the eyes below or on the frontal suture, the epigamic modifications of male head, antennae, maxillary palpi and often anterior legs, the labrum elongate and longitudinally furrowed or carinate, the shape of mouthparts and the endophallic structure (Bologna, 1991; Turco et al., 2003). Larvae are known only for six species of Cerocoma and one of Diaphorocera and their morphological features do not permit, unlike adult ones, a precise placement of the tribe within the subfamily (Bologna \& Pinto, 2001; Di Giulio et al., 2002; Turco et al., 2006). The biology of representatives of this tribe is summarised by Bologna (1991), and partially discussed by Di Giulio et al. (2002) and Turco et al. (2006) with regard to preimaginal stages, which do not have any phoretic behaviour, and by Turco et al. (2003) who account the sexual behaviour in the diverse genus Cerocoma.

In the context of our revision, after contributions on larval morphology, the genus Diaphorocera (8 species) was revised (Turco \& Bologna, 2007). The present contribution aims to clarify the phylogenetic relationships among all genera of the tribe, and to clarify the taxonomy of the less diverse genera, namely Anisarthrocera, Rhampholyssa, Rhampholyssodes and Somalarthrocera. The last is a new East African genus that includes a species from North Somalia previously referred to Anisarthrocera and a new species from Kenya. The last paper in the series will address the revision of the speciose genus Cerocoma (Turco \& Bologna, unpubl.).

The four genera revised here were poorly studied. Anisarthrocera is only briefly examined by Kaszab (1951) and Bologna (1990), who discuss some differences between the type species, A. batesi (Marseul, 1872), and $A$. semirufa (Fairmaire, 1882) referred to this genus by Kaszab (1951), but now transferred to the new genus Somalarthrocera. The taxonomy of Rhampholyssa 
was studied by Reitter (1889, 1906, 1909), Semenow (1895) and Kaszab (1951), while Rhampholyssodes was only compared to other genera when it was described (Kaszab, 1983), and some morphological traits were erroneously interpreted, namely the number of antennomeres.

These last three genera have narrow distributions in desert or semidesert areas of the Palaearctic Region, whereas the new genus from East Africa is a savannah element and represents interesting biogeographical evidence of the dispersal of Palaearctic fauna in the Afrotropical Region during late Cenozoic dry periods.

\section{MATERIAL AND METHODS}

For the taxonomic analysis the following specimens, including type material, were examined: Anisarthrocera batesi: holotype and 15 specimens, and the holotype, allotype, 8 paratypes and 6 additional specimens of the synonym $A$. $b$. villiersi; Rhampholyssa antennata: holotype, cotype, allotype, paratype and 3 additional specimens; Rhampholyssa steveni: 127 specimens, and the holotype and 9 additional specimens of the synonym $R$. komarowi; Rhampholyssodes pitcheri: 2 paratypes and 4 additional specimens; Somalarthrocera semirufa: lectotype, paralectotype and 2 additional specimens; Somalarthrocera savanicola: holotype.

The examined specimens are preserved in the following collections (associated acronyms reported in the text): BMNH Natural History Museum, London; HNHM - Hungarian Natural History Museum, Budapest; NMPC - National Museum, Department of Entomology, Prague; JHC - J. Hajek coll., Prague; MABC - M.A. Bologna coll., Università "Roma Tre", Roma; MCNV - Museo Civico di Storia Naturale, Venezia; MNHN - Muséum National d'Histoire Naturelle, Paris; PPT Plant Pests and Diseases Research Institute, Taxonomy Research Department, Tehran; SKC - S. Krejčík coll., Uničov, Czech Republic.

Specimen measurements and the morphological study, for both taxonomic and phylogenetic analyses, were made using an Olympus SZX12 stereomicroscope, while maps were prepared by means of Arcview 9.0 ESRI software.

In the study of phylogenetic relationships within the tribe Cerocomini, including Diaphorocera and Cerocoma (Figs 2-3), which are revised separately (Turco \& Bologna, 2007; unpubl.), we considered all the species referred to small genera (with one or two species) and some representatives of the most speciose ones. We included three Diaphorocera, representing the three lineages indicated by the phylogeny of this group (Turco \& Bologna, 2007), and four Cerocoma, representing the four known subgenera (Cerocoma, Metacerocoma, Mesocerocoma and Cerocomina). A total of thirteen species was included in the analysis.

Phylogenetic analysis was carried out using PAUP 4.0 software for PC (Swofford, 2002). Twenty-one adult morphological characters were considered for the cladistic analysis, and the list of these characters as well as the related matrix are presented in Appendices 1 and 2. Two taxa were constrained as outgroups: (a) Lytta vesicatoria (Linnaeus, 1758), a member of the Lyttini, a primitive tribe of Meloinae (see Bologna \& Pinto, 2001, 2002); (b) Pyrota akhurstiana Horn, 1891, belonging to the tribe Pyrotini, which molecular data indicate as closely related to the Cerocomini (Bologna et al., 2005). Both binary and multistate characters were considered, all elaborated as unordered and equally weighted, and processed by the branch-and-bound algorithm using "parsimony" as optimality criterion and the "furthest" addition sequence option. The accelerated transformation algorithm (ACCTRAN) was used to optimize characters on cladograms. Branch support was assessed using Bremer Support (BS) as well as Bootstrap and Jackknife Analyses (10,000 replicates). The computation of BS, was carried out by hand, starting from the most parsimonious tree (MPT) length and recomputing the branch-and-bound analysis keeping all trees of a certain length, each time increased by 1 step; the extra steps necessary to collapse a branch on the strict consensus of all the MPTs found so far have been counted, thus representing the BS for the branch. No consensus tree was computed since only one most parsimonious tree (MPT) was obtained.

\section{BIONOMICS}

The species of all genera are diurnal as far as known, and adult occurrence is primarily restricted to spring in the Palaearctic Region, with some summer records of Rhampholyssa, while Somalarthrocera adult activity seems related to the main monsoon season in East Africa.

According to the limited known locality details, Anisarthrocera batesi and Rhampholyssodes pitcheri live in eremic habitats. In southern Iran, A. batesi inhabits rocky or mixed desert, from sea level to about $1,500 \mathrm{~m}$ a.s.l., where it is active at least from late March (on the coast) to late May (on the plateau). We personally sampled in one of the two known localities of $R$. pitcheri (United Arab Emirates: Al Aïn, Bateen dunes, $270 \mathrm{~m}$ a.s.1.), a red sand dunes habitat with scarce herbaceous and bush vegetation blooming in spring (March-April). No information on host plants is available; records for this species range from mid March to mid May.

Both species of the genus Rhampolyssa are distributed in arid steppe or in semidesert and desert ecosystems in the Turanian depression from western Kazakhstan, east to Tajikistan, in localities from about sea level, or even lower in the Caspian depression, to more than $1,500 \mathrm{~m}$ a.s.l. Information about host plants is limited to one record of $R$. steveni on Haloxylon (Chenopodiaceae) in Uzbekistan. The phenology of $R$. steveni is restricted mainly to mid May to mid July, with a single record for April; no information is available on $R$. antennata.

One of us (MAB) collected Somalarthrocera semirufa in northern Somalia, at about $800 \mathrm{~m}$ a.s.l., on flowers of a small prostrate Acacia sp. (Fabaceae) in a semidesert ecosystem in the second half of May. The new species from Kenya was sampled in mid May by netting a strip of weeds along a road through open Acacia bushland separating open savannah from a wide marsh.

Sexual dimorphism is evident in the males of all the genera considered, mostly involving the structure of the head, antennae, and sometimes also anterior tibiae and maxillary palpi, but courtship behaviour has never been observed. Hosts of larval stages and the preimaginal development are unknown.

\section{PHYLOGENY}

As already reported, a cladistic analysis of the 6 cerocomine genera, with 13 species, was performed on 21 adult morphological characters (see Appendices 1 and 2).

The most parsimonious tree (MPT), obtained from the branch-and-bound analysis of 21 unordered and 


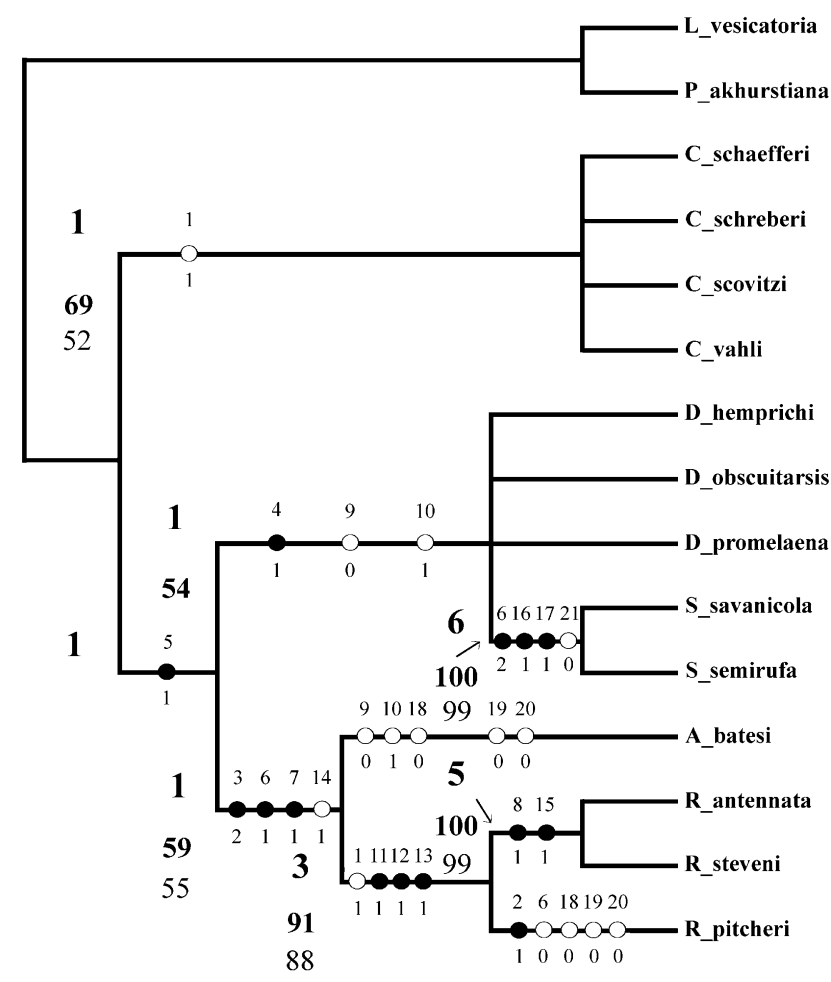

Fig. 1. Cladogram of the most parsimonious tree (MPT: Length $=34$; Consistency index, CI $=0,6765$; Homoplasy index, $\mathrm{HI}=0,3235$; Retention index, $\mathrm{RI}=0,8281$; Rescaled consistency index, $\mathrm{RC}=0,5602)$. The following indexes are indicated at each node: Bremer support, above branches; Bootstrap followed by Jackknife percentages $(>50 \%, 10,000$ replicates), below branches. Black circles represent non-homoplasious characters; white circles indicate homoplasies; numbers above circles represent characters, numbers below represent character states (see Appendix 1).

unweigthed characters (Fig. 1), led to the recognition of three distinct lineages: (a) a basally diverging clade including only Cerocoma, the most widely distributed (Palaearctic Region) and diverse genus of the tribe, characterised by many autapomorphic features, which could have evolved under strong sexual selection (Turco et al., 2003; Turco \& Bologna, unpubl.); (b) a clade that includes the genera Diaphorocera and Somalarthrocera distributed respectively in North and East Africa, with only two Diaphorocera species on the Arabian Peninsula and in southern Iran; (c) a clade including Anisarthrocera and the pair Rhampholyssa-Rhampholyssodes, which are very closely related.

The reduction in the number of antennomeres seems to represent a homoplasious condition, which occurred twice in the tribe, in Cerocoma and the clade RhampholyssaRhampholyssodes. Anisarthrocera, sistergroup of this last clade, shows the primitive character state (11 antennomeres), and represents the basal condition of a lineage characterised by having frontal calli forwardly protruded and elevated, particularly in Rhampholyssa-Rhampholyssodes. This clade is well supported (BS: 3; B: 91; J: 88 ) and is characterised also by the reduction of anterior tibial spurs, by a depression on the inner side of male fore tibiae, as well as by the non-metallic colour of elytra. The third lineage is represented by Diaphorocera and Somalarthrocera and is supported by a common secondary modification of male labrum. In addition the East African genus Somalarthrocera is strongly supported (BS: 6; B: 100; J: 99), and clearly distinct from Diaphorocera, as well as from all the other Cerocomini, because of the male genitalia, penis and endophallus in particular, evidence of the peculiar evolution this genus underwent during its isolation from the rest of the tribe since Pleistocene (see below).

\section{TAXONOMY}

\section{Account of genera and species}

\section{Genus Anisarthrocera Semenow, 1895}

Anisarthrocera Semenow, 1895: 517; Kaszab, 1951: 256, 273 (pars); Dvoř́ák, 1989: 5, 17 (pars); Bologna, 1990: 141-144 (pars); Bologna \& Pinto, 2002: 2056 (pars).

Type species: Rhampholyssa batesi Marseul, 1872, by monotypy.

Diagnosis (Fig. 4). Body slender and elongate, brownorange, subopaque except the head shiny, elytra apically or completely metallic violet-green, apex of mandibles black and legs partially black. Head capsule narrow and elongate, temples about 0.5 as long as longitudinal diameter of eye. Eyes elongate and obliquely extended to base of maxilla. Male frons with frontal calli only slightly protruding anteriad forming a low crest visible in lateral view, sloping anteriad; frons lateral to calli not depressed. Labrum longitudinally depressed in middle. Maxillary stipes elongate. Male palpomeres modified, IV less than twice as long as wide. Antennae with 11 antennomeres, subcylindrical and progresively longer in female, greatly modified in male, with antennomeres II-VIII transversally enlarged and variously shaped, middle segments with elongate setae, XI very slender and elongate. Pronotum very elongate, parallel sided, anterior third obliquely narrowed in male, progressively curved in female; male with an oblique furrow on each side of the anterior third. Tarsi unmodified and protibiae with two spurs in both sexes; male protibiae externally concave at base and with a pedunculate expansion about as long as $1 / 3$ of protibia. Black spiniform setae at apex of profemur and at base of protibia; similar setae at apex of meso- and metafemora, and on meso- and metatibiae. Both metatibial spurs spoon-like, depressed dorsally, the external one about twice the width of inner one. Mesosternum with anterior margin almost straight; mesepisterna well separated at base of inner margin. Elytra almost flat, with vestigial traces of two inner costae. Posterior margin of penultimate male abdominal visible sternite almost straight, last visible sternite depressed in middle and deeply V-emarginate, that of female rounded. Penis with two hooks, the distal one subapical, oblique and short; endophallus hook bidentate.

Remarks. The genus Anisarthrocera was described by Semenow (1895) to include Rhampholyssa batesi Marseul, 1872, easily distinguishable from other Rhampholyssa species by the number of antennomeres (11 in Anisarthrocera, 8 in Rhampholyssa). 


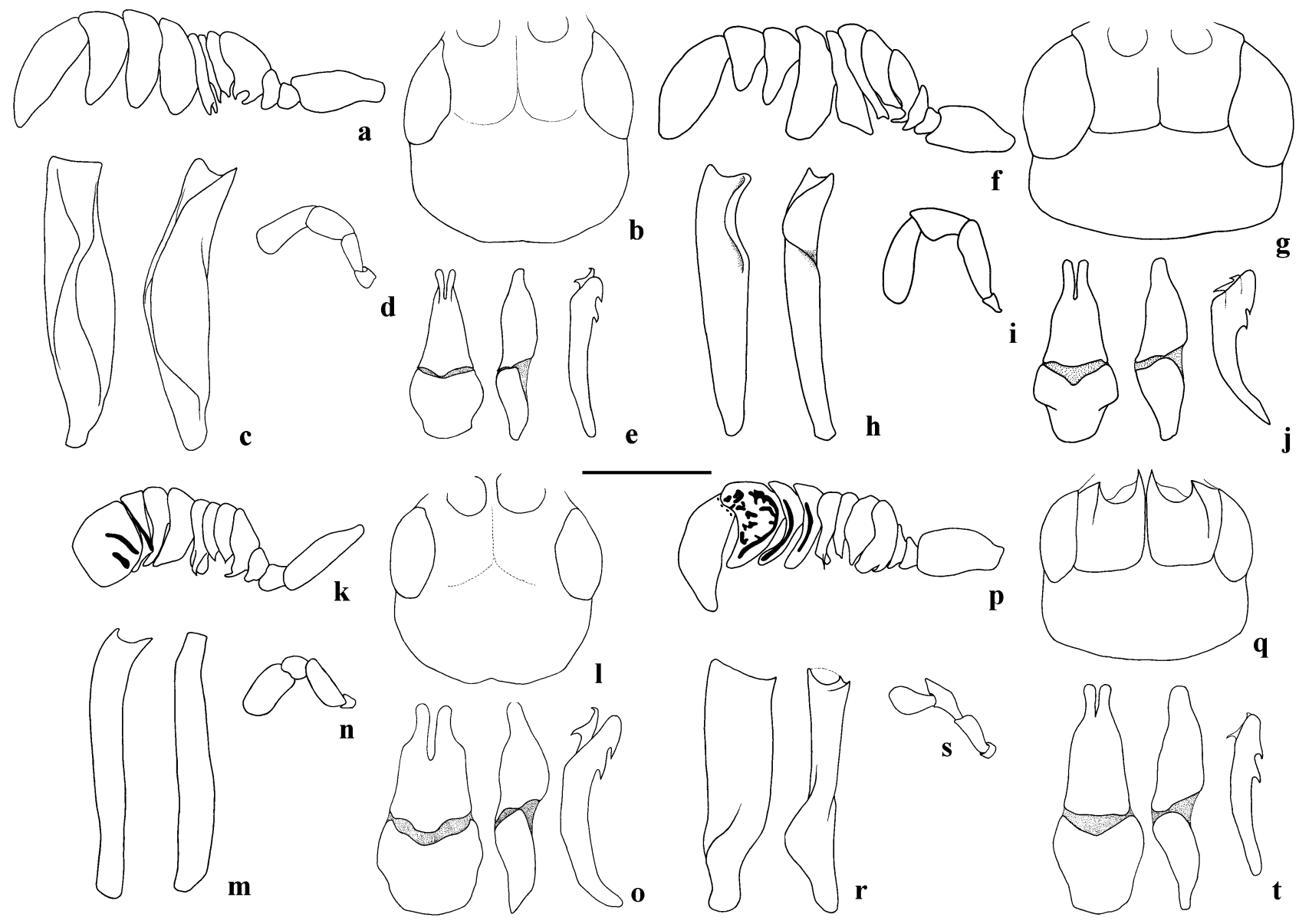

Fig. 2. Genus Diaphorocera (some representative species), male. a-e: D. hemprichi. a - right antenna, dorsal view; b - head, dorsal view; $\mathrm{c}$ - anterior tibiae, dorsal and lateral views; $\mathrm{d}$ - right maxillary palpus, dorsal view; e - genitalia (tegmen, dorsal and lateral views; penis, lateral view). $\mathrm{f}-\mathrm{j}$ : D. promelaena. $\mathrm{f}$ - right antenna, dorsal view; $\mathrm{g}$ - head, dorsal view; $\mathrm{h}$ - anterior tibiae, dorsal and lateral views; $\mathrm{i}$ - right maxillary palpus, dorsal view; $\mathrm{j}$ - genitalia (tegmen, dorsal and lateral views; penis, lateral view). $\mathrm{k}-0: D$. obscuritarsis. $\mathrm{k}$ - right antenna, dorsal view; 1 - head, dorsal view; $\mathrm{m}$ - anterior tibiae, dorsal and lateral views; $\mathrm{n}$ - right maxillary palpus, dorsal view; o - genitalia (tegmen, dorsal and lateral views; penis, lateral view). $\mathrm{p}$-t: $D$. sicardi. $\mathrm{p}$ - right antenna, dorsal view; $\mathrm{q}$ - head, dorsal view; $\mathrm{r}$ - anterior tibiae, dorsal and lateral views; $\mathrm{s}$ - right maxillary palpus, dorsal view; $\mathrm{t}-\mathrm{genitalia}$ (tegmen, dorsal and lateral views; penis, lateral view). Scale bar: $1 \mathrm{~mm}$.

Kaszab (1951) also referred Diaphorocera semirufa (Fairmaire) to Anisarthrocera, without examining types, and Bologna (1991) after studying types and new specimens, doubtfully retained this second species in Anisarthrocera. In the present study A. semirufa is transferred to the new genus Somalarthocera and consequently Anisarthrocera remains monotypic.

\section{Anisarthrocera batesi (Marseul, 1872)}

Rhampholyssa batesi Marseul, 1872: 416.

Anisarthrocera batesi: Semenow, 1895: 517; Kaszab, 1951:

273; Kaszab, 1968: 749; Dvořák, 1989: 17.

Anisarthrocera batesi batesi: Kaszab, 1968: 750.

Anisarthrocera batesi villiersi: Kaszab, 1968: 750, syn. n.

Type locality. "Arabie" (Marseul, 1872), without details; this name may not strictly indicate the present Saudi Arabia, but also the southern part of Iraq or Kouzestan (Iran), or other countries in the Arabian Peninsula. The type locality of the synonym $A$. batesi villiersi is "Bandar Abbas" (Kaszab, 1968), a coastal locality in the southern Iran.

Type material. The holotype $\delta$ we examined is preserved in BMNH and has the following labels: "Arabia" (white, handwrit- ten); "Rampholyssa / Batesi" (white, handwritten); "Rhampholyssa / Batesi Mars. / type." (white, handwritten); "F. Bates, / 81-19" (white, printed and on reverse side). The holotype lacks the following body parts: right anterior tarsomere V, left antenna (antennomeres I-II still present), left hind tarsomere IV and right hind tarsomeres III-IV.

In MNHN (Marseul's collection) one specimen we examined is labelled "Museum Paris / Coll. De Marseul"; "Kurdistan"; "Rhampholyssa / Batesi"; "Museum Paris / Coll. / De Marseul 1890" (azure, printed); "Batesi - Mars. Ab. 8. 416 Arab." (white, printed). According to the description (Marseul, 1872), the holotype is preserved in Bates' collection, and in our opinion the Paris specimen is not a syntype.

With regard to the types of the synonym $A$. batesi villiersi, we examined the following material (allotype and some paratypes are more or less damaged and lack some body parts). Holotype to with the following labels: "IRAN / Bandar Abbas / 29.III.1965" (white, printed and handwritten); "MUSEUM PARIS / Mission / Franco-Iranienne / 1965" (white, printed); "Holotypus 1967 ơ Anisarthrocera / batesi villiersi / Kaszab" [white, printed (in red)]; “Anisarthrocera / villiersi Kaszab / Dr. Z. Kaszab det. 1967" (white, printed and handwritten) (MNHN). Allotype $q(\mathrm{MNHN}), 1+$ paratype $(\mathrm{HNHM})$ and 3 paratypes 

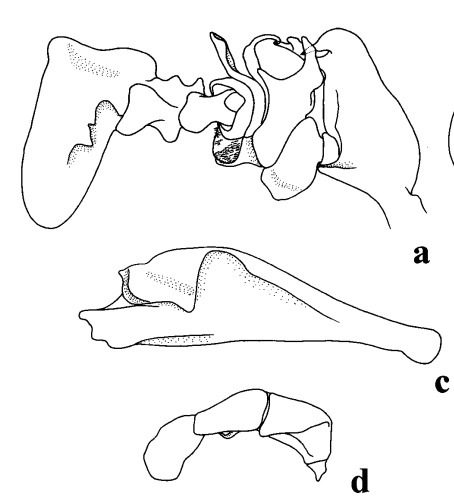

a
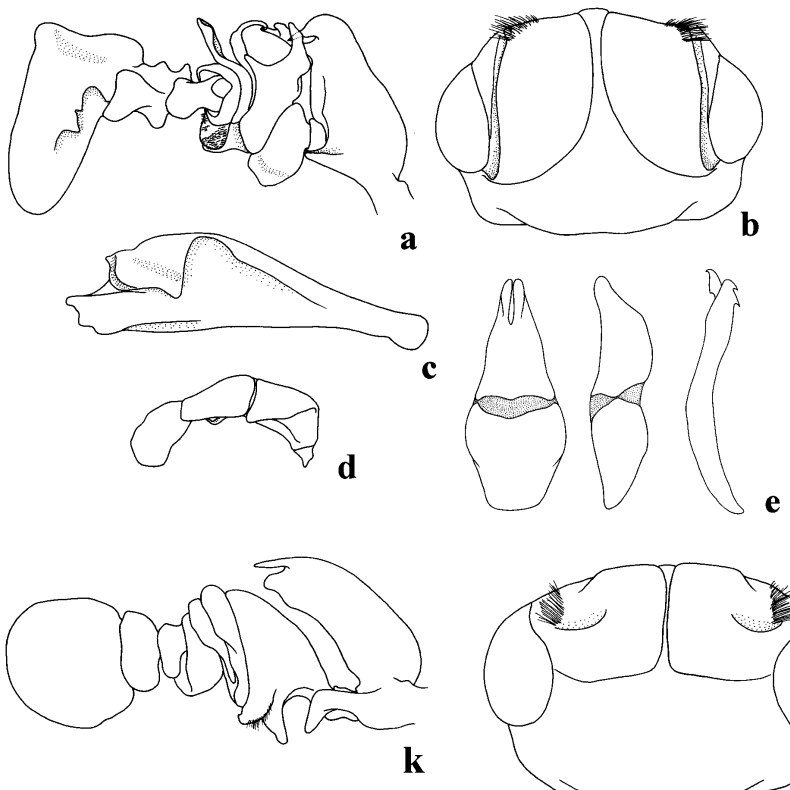

$\mathbf{k}$
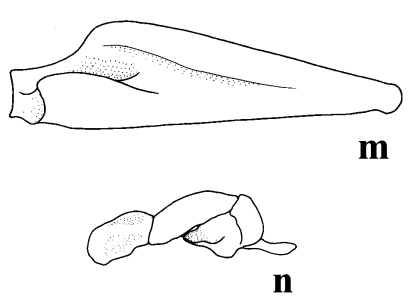

m
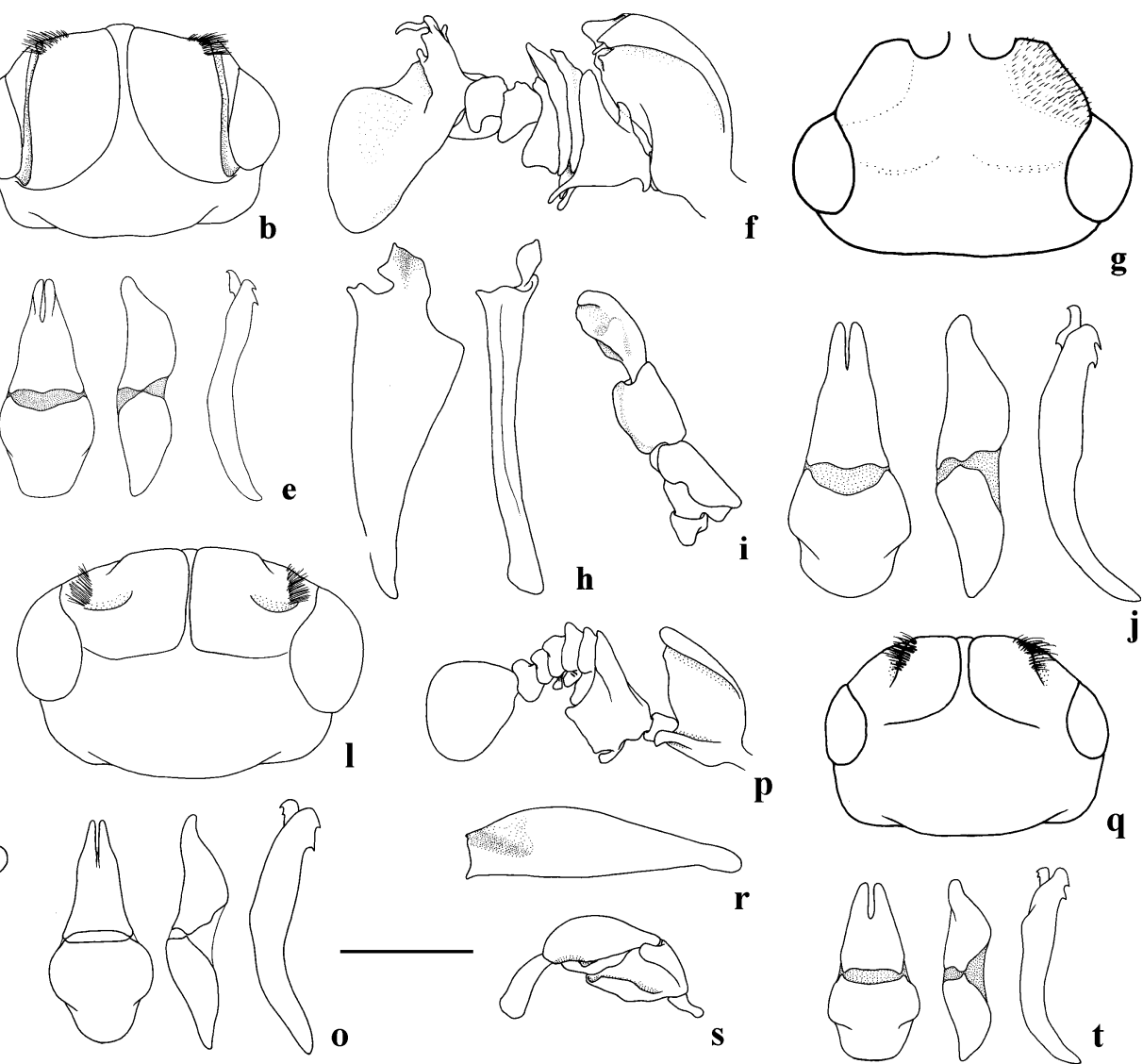

n

Fig. 3. Genus Cerocoma (some representative species), male. a-e: C. schreberi. a - left antenna, dorsal view; b - head, dorsal view; $\mathrm{c}$ - left anterior tibia, lateral view; $\mathrm{d}$ - right maxillary palpus, dorsal view; e - genitalia (tegmen, dorsal and lateral views; penis, lateral view). $\mathrm{f}-\mathrm{j}$ : C. scovitzi. f - left antenna, dorsal view; g - head, dorsal view; $\mathrm{h}$ - right anterior tibia, dorsal and lateral views; $\mathrm{i}$ - right maxillary palpus, dorsal view; $\mathrm{j}$ - genitalia (tegmen, dorsal and lateral views; penis, lateral view). $\mathrm{k}-\mathrm{o}$ : $C$. vahli. $\mathrm{k}-$ left antenna, dorsal view; 1 - head, dorsal view; $\mathrm{m}$ - left anterior tibia, lateral view; $\mathrm{n}$ - right maxillary palpus, dorsal view; $\mathrm{o}$ - genitalia (tegmen, dorsal and lateral views; penis, lateral view). $\mathrm{p}-\mathrm{t}$ : C. schaefferi. $\mathrm{p}$ - left antenna, dorsal view; $\mathrm{q}$ - head, dorsal view; $\mathrm{r}$ - left anterior tibia, lateral view; $\mathrm{s}$ - right maxillary palpus, dorsal view; $\mathrm{t}$ - genitalia (tegmen, dorsal and lateral views; penis, lateral view). Scale bar: $1 \mathrm{~mm}$.

(MNHN), with the same labels as the holotype, but "Bandar Abbas / 29.III.1965", "Allotypus..." or "Paratypus". Paratypes: $2 \sigma^{\star}(\mathrm{HNHM}), 1 \delta^{t}$ and 2 other specimens (MNHN) with the following labels: "IRAN / Bandar Abbas / $25 \mathrm{~km} \mathrm{~W} \mathrm{/}$ 28.29.III.1965" (white, printed and handwritten); "MUSEUM PARIS / Mission / Franco-Iranienne / 1965" (white, printed); "Paratypus 1967, Anisarthrocera / batesi villiersi. Kaszab" (white, printed and handwritten) (two male paratypes with an additional label "Anisarthrocera / batesi villiersi Kasz. / M.A. Bologna det. 2004" (white, printed and handwritten) (HNHM).

Identification (Fig. 4). Characters of the genus. Maximal length: $15.3 \mathrm{~mm}$; maximal width at base of elytra: $3.3 \mathrm{~mm}$. Setation white-yellow; the metallic violet colouration of elytra extends onto the apical fourth in most populations, but elytra are completely violet-green in the populations in the coastal area of south Iran near Bandar-Abbas and Baluchistan. Head (Fig. 4b, 4f) and pronotum (Fig. 4g) surface almost smooth, head shiny and pronotum subopaque; pronotum of the female with sparse but large punctures. Temples, genae and ventral side with denser and longer setae, elytra with denser but shorter setae. Male antennae greatly modified as in Fig. 4a. Female antennomere I-III with long and dark setae,
IV-XI with dense, short and light setae; antennomere I cylindrical, elongate as long as II-V together; II short and narrow; III very short and narrow, apparently almost fused to IV; IV-XI similar in width but progressively longer, IV short, V-VII subequal in size, VIII-X cylindrical, more than twice as long as VII and two times as long as wide, XI 1.5 as long as X, with slender and narrower apical third. Male maxillary palpus as in Fig. 4e; male protibia as in Figs 4c, d; male genitalia as in Fig. 4h.

Remarks. The two described subspecies appear moderately differentiated only by the elytral metallic colour, only apical in the nominate form and complete in the phenotype villiersi. The antennomere differences proposed by Kaszab (1968) are weak and not diagnostic. Consequently, we propose the following synonymy: Anisarthrocera batesi (Marseul, 1872) = Anisarthrocera batesi villiersi Kaszab, 1968, syn. n.

Distribution. (Fig. 5) Iraq (?) (Kurdistan): in addition to the Paris' specimen previously discussed, Kaszab (1983) cited a second Kurdistan specimen examined, preserved in the Fry collection (BMNH), labelled "Turcom.a Kurd, Millingen". Another specimen with the same label is preserved in HNHM. Millingen was an English officer who travelled from Adana (S Turkey), 


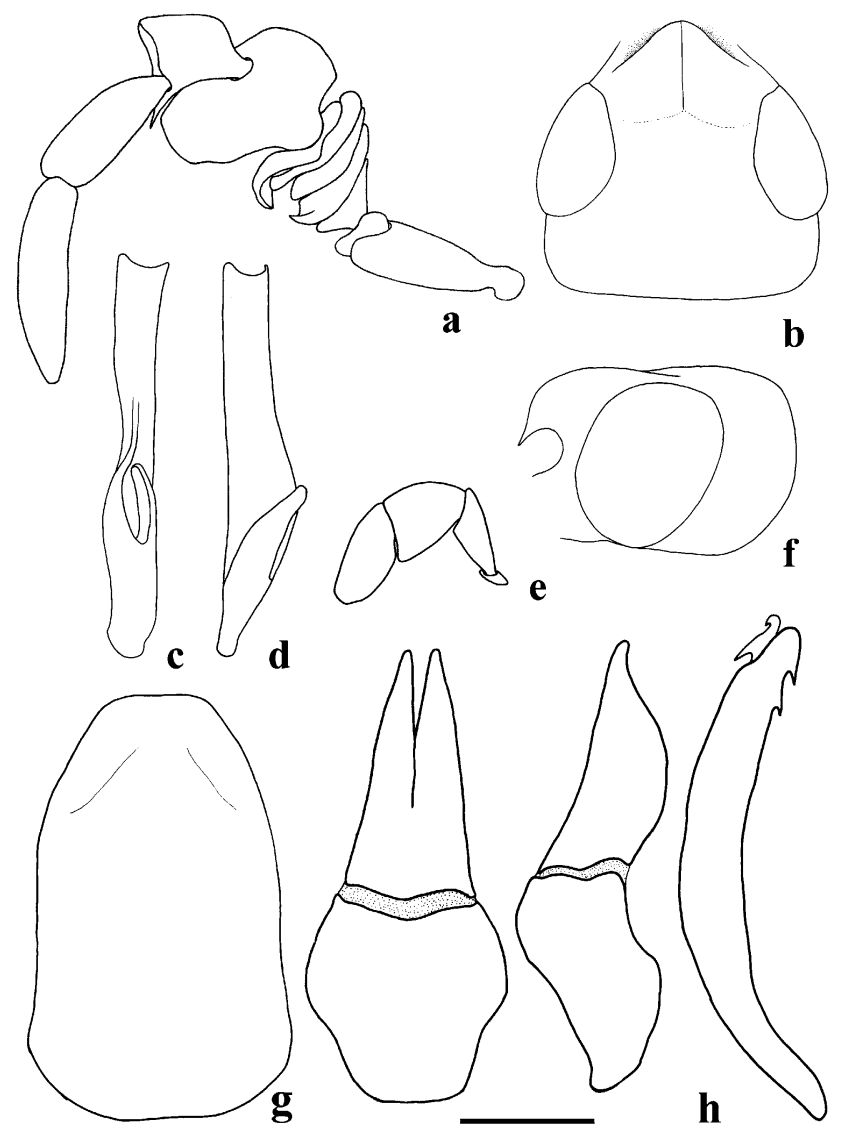

Fig. 4. Anisarthrocera batesi, male. a - left antenna, dorsal view; $\mathrm{b}$ - head, dorsal view; $\mathrm{c}$ - right anterior tibia, dorsal view; $\mathrm{d}$ - left anterior tibia, lateral view; e - left maxillary palpus, ventral view; $\mathrm{f}$ - head, lateral view; $\mathrm{g}$ - pronotum, dorsal view; $\mathrm{h}$ - genitalia (tegmen, dorsal and lateral views; penis, lateral view). Scale bar: $1 \mathrm{~mm}$ (b-d, f-g); $0.75 \mathrm{~mm}(\mathrm{a}, \mathrm{e}) ; 0.5 \mathrm{~mm}$ (h).

east to Ottoman Kurdistan through the present countries of Turkey, Syria and Iraq, in the second half of XIX century, and probably collected in this area. Iran: Iran (Dvořák, 1989; BMNH). Khouzestan: Masjed Soleiman (PPT); Susangerd (PPT). Fars: Fars (Modarres Awal, 1997); Shiraz (Mirzayans, 1970); Shiraz, Soltanabad (Kaszab, 1968; HNHM, also phenotype villiersi); Borazdjan (Mirzayans, 1970); Chabankareh (Mirzayans, 1970); Lar (PPT). Boushehr: Boushehr (Modarres Awal, 1997). Hormozgan (most of the specimens from this province belong to the phenotype villiersi): Hormozgan (Modarres Awal, 1997); 25 km W Bandar Abbas (Kaszab, 1968); Bandar Abbas (Kaszab, 1968); 16 km E Bandar Abbas (Dvořák, 1996; HNHM); Bandar-lengueh (Mirzayans, 1970). Kerman: Djroft (MABC, PPT). Balouchstan: Tis, Oman Sea (JHC, phenotype villiersi). Saudi Arabia (?): Arabia (Marseul, 1872; Kaszab, 1951; Bologna, 1990). Actually, the old generic citations from "Arabia" could refer to other countries such as Iraq or Jordan.

\section{Genus Somalarthrocera gen. $n$.}

Type species: Diaphorocera semirufa Fairmaire, 1882, by present designation.

Diagnosis. The only Afrotropical genus of the tribe Cerocomini, close to Diaphorocera Heyden. See key to genera for diagnostic characters.
Description (Fig. 6). Body elongate but robust, orange, head partially or completely black, thorax and antennae partially black, tarsi black, elytra violet or green metallic.

Head capsule transverse and short, temples slightly shorter than longitudinal diameter of eye. Eyes elongate and wide, obliquely extended to base of maxilla. Male frons with calli short and raised, in front abruptly sloping, not forming a carina; frons lateral to calli not evidently depressed. Labrum in middle with a longitudinal, smooth, glabrous, narrow and incomplete arch, projecting over labral surface, starting from anterior third but not reaching the base. Female frons slightly depressed and smooth. Maxillary stipes elongate. Male palpomeres modified, II-IV widened and depressed, II triangularly widened anteriad, depressed, foliaceous, IV twice as long as wide, depressed, foliaceous. Antennae with 11 antennomeres, all segments more or less modified in male, the middle antennomeres transversally widened, XI very elongate; female antennomeres II-X short, subtrapezoidal, only I and XI elongate.

Pronotum elongate, parallel-sided, straight and converging in anterior third in male, and roundly converging in female; male with an oblique moderately deep furrow on each side on anterior third. Tarsi unmodified and protibiae with two spurs in both sexes; male protibiae without any particular modification; no spiniform setae on anterior legs. Metatibial spurs both spoon-like or the inner one spiniform. Mesosternum with anterior margin almost straight; mesepisterna well separated at base of inner margin. Elytra almost flat, with vestigial traces of two inner costae.

Posterior margin of penultimate male visible abdominal sternite almost straight, last visible sternite depressed in middle, deeply and widely $\mathrm{V}$-emarginate, that of female rounded. Penis with only one apical hook; endophallus hook unidentate.

Affinities. Relationships of this new genus are discussed in the phylogenetic analysis (see above).

Remarks. Bologna (1990) remarked on the biogeographical interest of the occurrence of a cerocomine representative in the East African fauna, because the tribe is otherwise distributed exclusively in the Palaearctic Region. The presence of S. semirufa (cited as Anisarthrocera), as well as other Saharo-Mediterranean elements (such as Alosimus somalicus Kaszab, 1951 and Meloe vignai Bologna, 1990) in the semidesert area of Somalia, was explained by Bologna (1990) as the result of restricted dispersal events, which probably occurred in a humid phase of the Pleistocene.

Actually, the occurrence of an endemic genus in East Africa to southern Kenya belonging to a Palaearctic tribe, may be related to a more general biogeographical model of disjunct distribution, due to vicariance events caused by the repeated pulsations of the Sahara desert (see Bologna et al., 2008). During one of the documented dry periods, the desert conditions of this area may have isolated the North and East African habitats available to the cerocomine ancestral lineage, which led to the present Somalarthrocera-Diaphorocera clade. The close rela- 


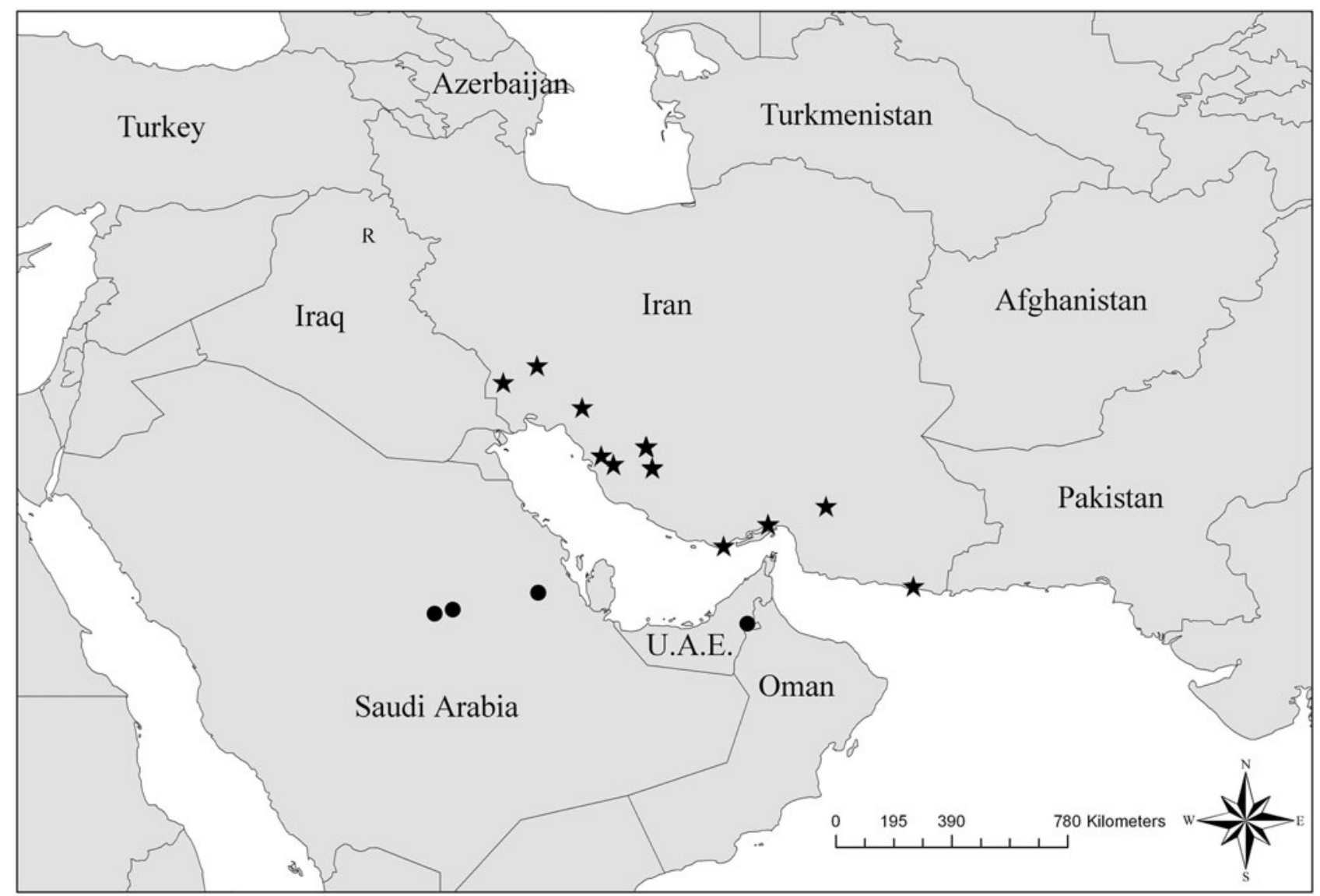

Fig. 5. Distribution of Anisarthrocera batesi (stars and $\mathrm{R}$ in Iraq, as generic record of Kurdistan) and Rhampholyssodes pitcheri (circles).

tionship between these genera, respectively East African and Saharo-Arabian, greatly supports this hypothesis of a late, probably Mio-Pliocenic cladogenetic event that fragmented this lineage.

\section{Somalarthrocera savanicola sp. $\mathbf{n}$.}

Type material. Holotype $\delta$ Kenya, Tsavo East, between Aruba Lodge and Voi Gate, 26.v.2006, D. Avesani, G. Carpaneto, P. Cerretti, G. Nardi coll. (MABC). This specimen was collected by sweep netting weeds along a dirt road, crossing Acacia bushland in a mixture of marshes and open savannah habitats.

Diagnosis. A Somalarthrocera easily distinguished from the only other congeneric species, S. semirufa (see key to species).

Description (Fig. 6). Characters of the genus. Maximal length: $8.0 \mathrm{~mm}$; maximal width at base of elytra: $2.0 \mathrm{~mm}$.

Head (Fig. 6b, 6c) black, with vague metallic reflections, labrum, clypeus and mandibles orange, the latter apically black, antennae orange but antennomeres VIII (partially) and IX black; prothorax orange with two small anterior black spots on sides of pronotum, meso- and metathorax black with blue reflections; legs yellow, meso- and metacoxae black, lighter at apex, tarsi black; elytra metallic green with blue reflections on external margins; posterior margin of penultimate visible abdominal segment black. Setation yellow, denser on ventral surface, genae and legs.
Head capsule punctures sparse and only shallow. Male frontal calli with straight anterior margin, without any particular modifications. Labrum with a distinct arcuate structure slightly projecting from surface; male maxillary palpi as in Fig. 6f. Antennomeres as in Fig. 6a, antennomere IX wide but not strongly transverse.

Pronotum (Fig. 6d) slightly longer than wide, sides enlarging from base to middle and slightly narrowing anteriad; anterior oblique depressions not very deep; punctures as on head. Male protibiae in lateral view slightly curved dorsally, in dorsal view as in Fig. 6e. Metatibial spurs both spoon-like, the external one wider.

Parameres in dorsal and ventral views as in Fig. 6g; penis as in Fig. $6 \mathrm{~g}$.

Female unknown.

Distribution (Fig. 7). Kenya (Coast): Tsavo East, between Aruba Lodge and Voi Gate (MABC).

Somalarthrocera semirufa (Fairmaire, 1882) comb. n.

Diaphorocera semirufa Fairmaire, 1882: 82.

Anisarthrocera semirufa: Kaszab, 1951: 273; Dvořák, 1989: 17; Bologna, 1990: 356.

Type locality. "Pays Çomalis". As explained by Bologna (1990), even though Fairmaire (1882) did not give the exact locality, the information on the Revoil's travel probably indicates that the type specimens were collected in Migurtinia, North Somalia. 

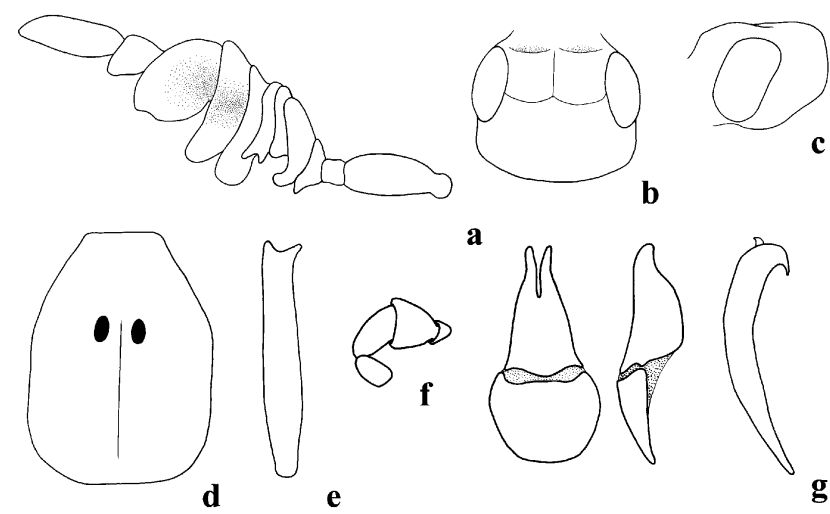

a

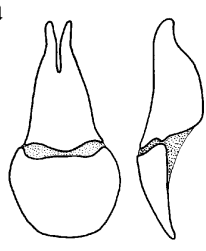

b

c
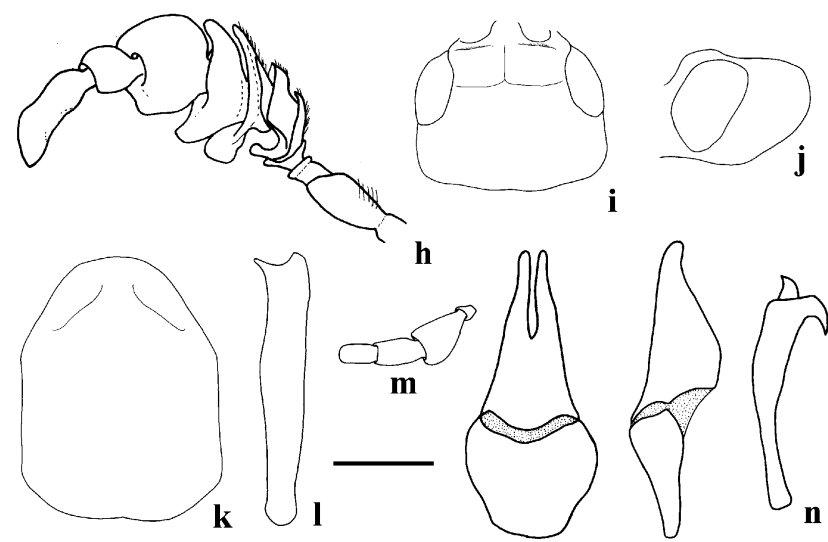

Fig. 6. Genus Somalarthrocera, male. a-g: S. savanicola. aright antenna, dorsal view; $\mathrm{b}$ - head, dorsal view; $\mathrm{c}-$ head, lateral view; $\mathrm{d}$ - pronotum, dorsal view; e - right anterior tibia, dorsal view; $\mathrm{f}$ - right maxillary palpus, dorsal view; $\mathrm{g}$ - genitalia (tegmen, dorsal and lateral views; penis, lateral view). $\mathrm{h}-\mathrm{p}$ : S. semirufa. h - right antenna, dorsal view; i - head, dorsal view; $\mathrm{j}$ - head, lateral view; $\mathrm{k}$ - pronotum, dorsal view; 1 - left anterior tibia, dorsal view; $\mathrm{m}$ - left maxillary palpus, dorsal view; $\mathrm{n}$ - genitalia (tegmen, dorsal and lateral views; penis, lateral view). Scale bar: $1 \mathrm{~mm}(\mathrm{i}-1) ; 0.75 \mathrm{~mm}$ (b-e, h, m); $0.5 \mathrm{~mm}$ $(a, f, g, n)$.

Type material. Lectotype $\delta$ with the following labels: "1727, 81" (azure, rounded and on reverse side, handwritten); "Diaphorocera / semirufa / Frm" (white, handwritten); "LECTOTYPUS / Diaphorocera / semirufa Fairmaire / M. Bologna des. 988" (red, printed and handwritten); "Anisarthrocera / semirufa (Fairmaire) / M. Bologna det. 1988" (white, printed and handwritten) (MNHN). Paralectotype $q$ with the same labels, but "1726" and "Paralectotypus..." (MNHN). The lectotype lacks left hind leg (except coxa, trochanter and the base of femur) and right anterior tarsus. The paralectotype partially covered by whitish mould and lacks left anterior leg (except coxa and trochanter).

Identification (Fig. 6). See Bologna, 1990 for a more detailed description. Similar to $S$. savanicola, except for the following characters.

Maximal length: $12.9 \mathrm{~mm}$; maximal width at base of elytra: $3.4 \mathrm{~mm}$. Head (Figs 6i, 6j) dark orange, with a darker or almost black colouration on the anterior half, more or less extended posteriad in middle; frons partially orange in middle in female. Smooth and glabrous arcuate structure of labrum distinctly projecting from the surface. Male antennomeres as in Fig. 6h, IX subtransverse, very

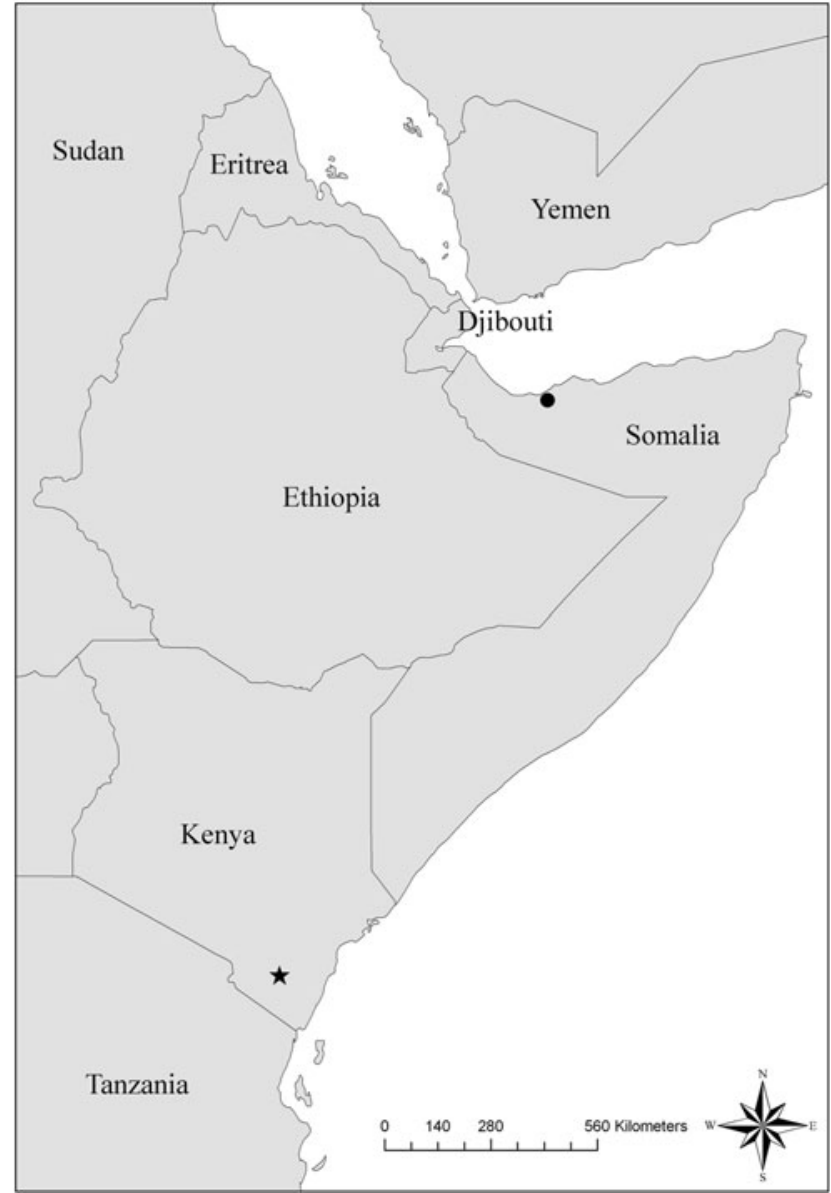

Fig. 7. Distribution of Somalarthrocera semirufa (circle) and S. savanicola (star).

wide. Male maxillary palpi as in Fig. 6m. Pronotum (Fig. $6 \mathrm{k}$ ) unicoloured orange, elongate and with parallel sides, not enlarged in middle, slightly narrowed on anterior third and with deep oblique furrows in male, only slightly rounded on anterior third with a vague middle longitudinal depression in female; apex of protibiae with a digitiform extension outwardly directed, more robust and elongate in female, in dorsal view as in Fig. 61; mesothorax orange, metathorax black without metallic reflections, elytra metallic violet; metatibial spurs dissimilar, the inner one spiniform, outer spoon-like. Abdomen unicoloured orange-red. Male genitalia as in Fig. 6n.

Distribution (Fig. 7). Somalia: Somalia (Fairmaire, 1882; Kolbe, 1897; Cros, 1939; Kaszab, 1951; Dvořák, 1989; Bologna, 1990; MNHN). Hargeysa: West Galbeed, Tog Marmarood (Bologna, 1990; MABC).

\section{Key to species}

1 Body longer $(12.9 \mathrm{~mm})$. Head orange but dark or almost black on anterior half; labrum with a smooth and glabrous arch distinctly projecting from surface; male antennomere IX very wide; pronotum orange-red, parallel sided; mesothorax orange, metathorax black; elytra metallic violet; inner metatibial spur spiniform, outer spoon-like. ......... $\ldots \ldots \ldots \ldots \ldots \ldots \ldots \ldots$. semirufa 

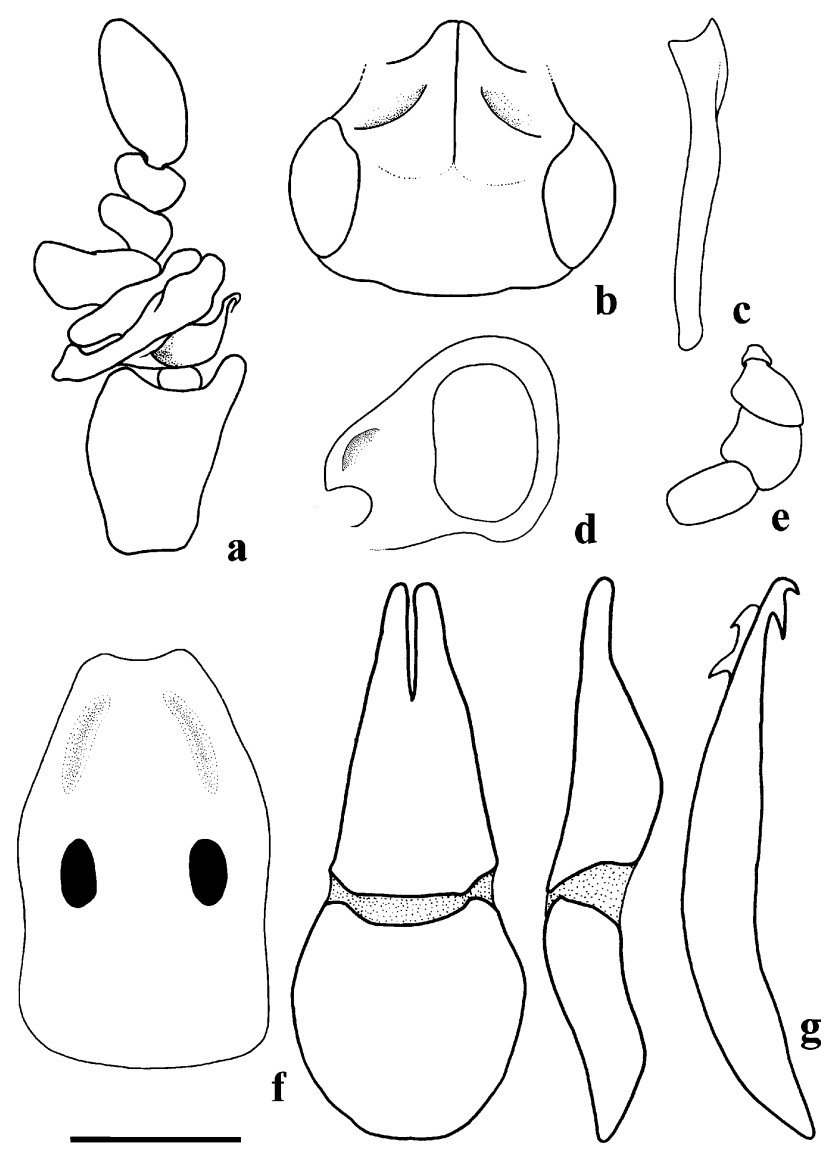

Fig. 8. Rhampholyssodes pitcheri, male. a - right antenna, dorsal view; $\mathrm{b}$ - head, dorsal view; $\mathrm{c}$ - left anterior tibia, dorsal view; $\mathrm{d}$ - head, lateral view; e - left maxillary palpus, dorsal view; $\mathrm{f}$ - pronotum, dorsal view; $\mathrm{g}$ - genitalia (tegmen, dorsal and lateral views; penis, lateral view). Scale bar: $1 \mathrm{~mm}(\mathrm{~b}-\mathrm{d}, \mathrm{f})$; $0.75 \mathrm{~mm}(\mathrm{a}, \mathrm{e}) ; 0.5 \mathrm{~mm}(\mathrm{~g})$.

- Body shorter $(8.0 \mathrm{~mm})$. Head completely black, with metallic reflections; arcuate structure on labrum only slightly projecting from the surface; male antennomere IX less wide; pronotum orange with one black spot on each side, wider in middle; meso- and methathorax black with blue metallic reflections; elytra green metallic, blue metallic on external margins; both metatibial spurs spoon-like. . . . . . . .......................... savanicola $\mathrm{sp.}$ n.

\section{Genus Rhampholyssodes Kaszab, 1983}

Rhampholyssodes Kaszab, 1983: 182; Dvořák, 1989: 5, 17; Bologna, 1990: 141-144; Bologna \& Pinto, 2002: 2058.

Type species. Rhampholyssodes pitcheri Kaszab, 1983, by monotypy.

Diagnosis (Fig. 8). Body slender and elongate, brownorange, shiny, without any metallic colouration, but elytra with a black middle spot and apex widely black, metathorax black. Head capsule narrow and elongate, temples extremely short. Eyes elongate and obliquely extended to the base of maxilla. Male (Figs 8b, 8d) with frontal calli flat but anteriad evidently protruding and forming a flat crest visible in lateral view, well distinct because the frons lateral to calli is distinctly depressed. Labrum longitudinally depressed in middle. Maxillary stipes elongate. Male palpomeres greatly modified (Fig. 8e), IV less than
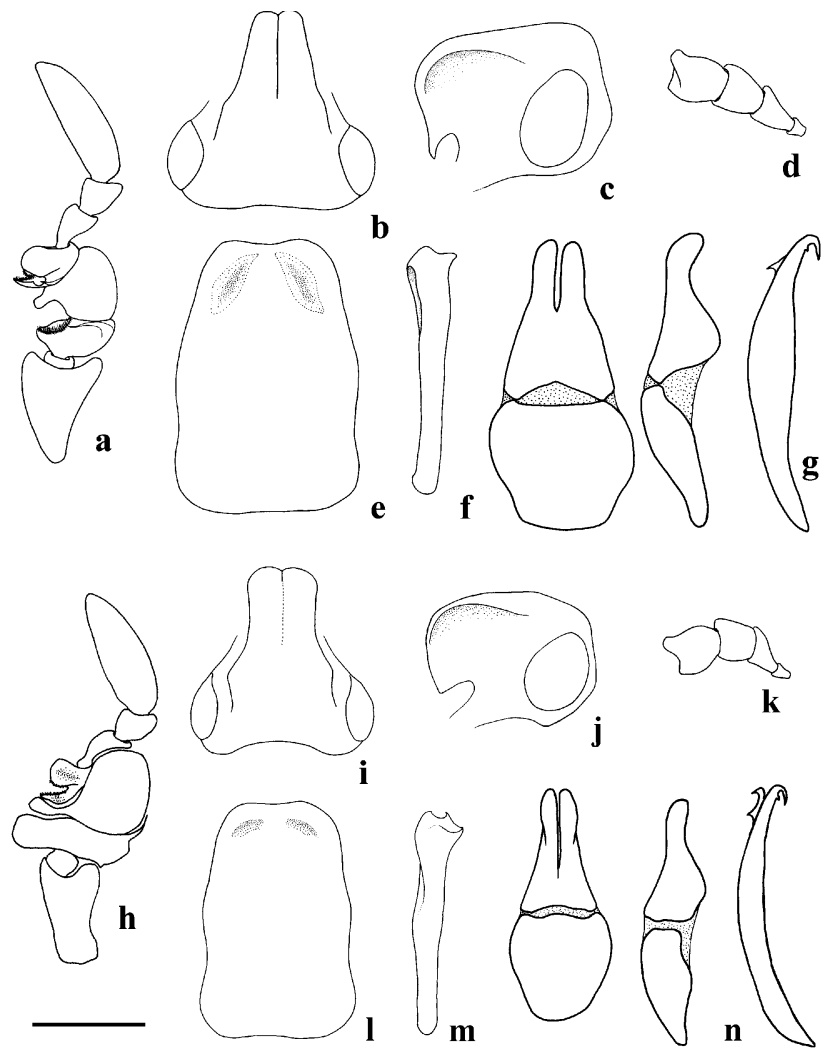

Fig. 9. Genus Rhampholyssa, male. a-g: R. antennata. a right antenna, dorsal view; $\mathrm{b}$ - head, dorsal view; $\mathrm{c}-$ head, lateral view; $\mathrm{d}$ - left maxillary palpus, ventral view; e - pronotum, dorsal view; $\mathrm{f}$ - right anterior tibia, dorsal view; $\mathrm{g}$ - genitalia (tegmen, dorsal and lateral views; penis, lateral view). $\mathrm{h}-\mathrm{n}: R$. steveni. $\mathrm{h}$ - right antenna, dorsal view; $\mathrm{i}$ - head, dorsal view; $\mathrm{j}$ head, lateral view; $\mathrm{k}$ - left maxillary palpus, ventral view; 1 pronotum, dorsal view; $\mathrm{m}$ - right anterior tibia, dorsal view; $\mathrm{n}$ genitalia (tegmen, dorsal and lateral views; penis, lateral view). Scale bar: $1 \mathrm{~mm}$ (b-c, e, f, i-j, l, m); $0.75 \mathrm{~mm}$ (a, d, h, k); 0.5 $\mathrm{mm}(\mathrm{g}, \mathrm{n})$.

twice as long as wide. Antennae with 9 antennomeres, not clearly distinct in male (Fig. 8a); female antennomeres not evidently modified, only VII-VIII wider than previous ones; III-IV in some cases partly fused; male antennomeres strongly modified, I enormous, long and depressed, II-VI variously shaped, IX elongate. Pronotum (Fig. 8f) very elongate, in both sexes parallel-sided and anterior third obliquely narrowed, more evident in male. Tarsi unmodified and protibiae with only one spur in both sexes; male protibiae not evidently modified, but curved at base on inner side and externally on anterior half, apically enlarged and slightly depressed on inner side (Fig. 8c); female protibiae not modified; legs without spiniform setae. Metatibial spurs elongate, even if robust, the inner one pointed, the outer stick-like. Mesosternum with anterior margin curved; mesepisterna well separated at base of inner margin. Elytra slightly flattened, external margin in middle slightly sinuate. Posterior margin of penultimate male abdominal visible sternite almost straight, last visible sternite slightly depressed in middle and moderately $\mathrm{V}$-emarginate, that of female rounded. 


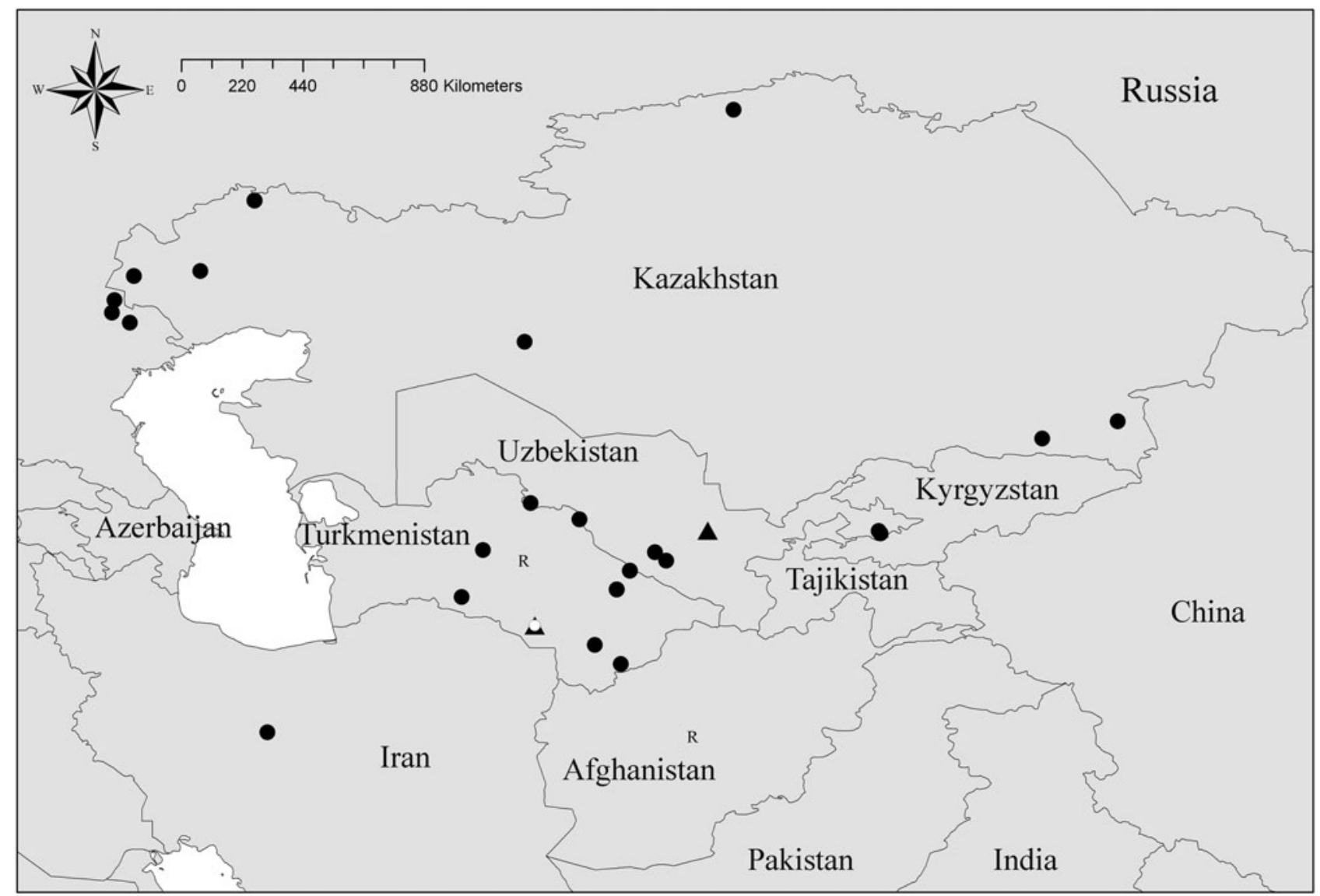

Fig. 10. Distribution of Rhampholyssa antennata (triangles and $\mathrm{R}$ in Turkmenistan, as generic record) and R. steveni (circles and $\mathrm{R}$ in Afghanistan, as generic record).

Penis (Fig. 8g) with two hooks, the distal one subapical, oblique and short; endophallus hook bidentate (Fig. 8g).

Remarks. In agreement with Bologna \& Pinto (2002), the monotypic genus Rhampholyssodes has nine antennomeres and not ten, as Kaszab (1983) described and figured. The female antennomeres III-IV are sometimes partly fused so that the proper number may be misinterpreted.

\section{Rhampholyssodes pitcheri Kaszab, 1983}

Rhampholyssodes pitcheri Kaszab, 1983: 182-183; Dvořák, 1989: 17; Bologna \& Pinto, 2002: 2058.

Type locality. "Saudi Arabia, Eastern Prov., Mishash, Al Udhailiyah" (Kaszab, 1983).

Type material. Holotype and some paratypes, not studied, are preserved in Pitcher's collection, in Manchester, UK. We examined the following specimens: paratype $\delta$ with the following labels: "SAUDI ARABIA / Eastern Prov. / D.A. Pitcher" (white, printed); "Mishash, Al / Udhailiyah, 29.iv. / 1982, no. 172" (white, printed); "Paratypus 1983 oิ / Rhampholyssodes / pitcheri / Kaszab" (white with red frame, printed and handwritten). Paratype $q$ with the same labels as the male, except for the last one: "Paratypus 1983 o / Rhampholyssodes / pitcheri / Kaszab" (HNHM).

Identification (Fig. 8). Characters of the genus. Maximal length: $12.0 \mathrm{~mm}$; maximal width at base of elytra: 2.7 $\mathrm{mm}$. Setation white-yellow. Black elytral colouration not evidently variable. Head and pronotum very shiny and smooth. Temples, genae and ventral part of body with denser and longer setae, elytra with dense but shorter setae. Male antennomeres greatly modified as in Fig. 8a. Female antennae simple. Pronotum of male with an oblique and very deep furrow on each side on anterior third; anterior third of female pronotum transversally slightly depressed. Male genitalia as in Fig. 8g.

Distribution (Fig. 5). Saudi Arabia: Saudi Arabia (Dvořák, 1989). Ar Riyad Province: Riyadh (HNHM). Eastern Province: Jaww Dukha (Kaszab, 1983); Udhailiyah Camp (Kaszab, 1983); Mishash, Al Udhailiyah (Kaszab, 1983). United Arab Emirates: Abu Dhabi Emirate: Al Aïn, Bateen Dunes (Bologna \& Turco, 2007; MABC; SKC).

\section{Genus Rhampholyssa Kraatz, 1863}

Rhampholyssa Kraatz, 1863: 110; Semenow, 1895: 516-517; Reitter, 1909: 102-103; Kaszab, 1951: 256-257, 270; Dvořák, 1989: 5, 17; Bologna, 1990: 141-144; Bologna \& Pinto, 2002: 2057.

Type species. Cerocoma steveni Fischer von Waldheim, 1824, by monotypy.

Diagnosis (Fig. 9). Body slender and elongate, shiny brown-orange, without metallic colouration, some antennomeres and palpi black or yellow; other parts of body black in some specimens (occiput and frontal carina, apex of elytra, meso- and metathorax, apex of meso- and metatibiae and tarsi). Setation white-yellow, denser and longer on meso- and metathorax and legs, sparser but long on abdomen, shorter on the remaining parts of body. Head 
capsule narrow and elongate, male temples extremely short, almost indistinguishable in dorsal view, female temples very short. Eyes elongate and obliquely extended to base of maxilla. Male frontal calli greatly protruding to form a high and curved crest, well visible in lateral view, very high anteriad; frons, laterally to calli with a wide depression. Labrum longitudinally depressed in middle. Maxillary stipes elongate. Male palpomeres very modified, IV less than twice as long as wide. Antennae with 8 antennomeres, very modified in male, subcylindrical and progressively wider from IV to VII in female, XI slender and elongate. Pronotum in both sexes very elongate, parallel-sided, anterior third obliquely narrowed; pronotum of the male with a subtransverse deep, wide and long furrow on each side of anterior third; pronotum of the female only transversally depressed, without distinct furrows. Protarsi unmodified and protibiae with only one spur in both sexes; male protibiae straight at base, externally slightly curved at apex and depressed, inner side widened and depressed; female protibiae not modified; legs without spiniform setae. Metatibial spurs both spoonlike or the inner one pointed. Mesosternum with anterior margin curved; mesepisterna well separated at base of inner margin. Elytra slightly flattened, external margin in middle slightly sinuate. Posterior margin of penultimate male abdominal visible sternite almost straight, last visible sternite slightly depressed in middle and widely but not deeply $\mathrm{V}$-emarginate, that of female rounded. Penis with two hooks, the distal one subapical, oblique and short; endophallus hook bidentate.

\section{Rhampholyssa antennata Reitter, 1906}

Rhampholyssa antennata Reitter, 1906: 36; Kaszab, 1951: 256, 270; Dvořák, 1989: 17.

Type locality. "Transcaspien: Oase Tedschen" (Reitter, 1906).

Type material. Holotype $\delta$ examined with the following labels: "Transcaspien / Oase Tedshen / 5.1903. Coll. Hauser" (white, printed); "Holotypus 1906 / Rhampholyssa ô antennata / Reitter" (white, red printed and handwritten) (HNHM). Allotype $q$ and paratype $\delta$ both examined, with the same labels as holotype, but "Allotypus 1906" and "Paratypus 1906" respectively (HNHM). Paratype $\delta$ examined with the following labels: "Transcaspien / Oase Tedshen / 5.1903. Coll. Hauser" (white, printed); "Rhampholyssa / antennata / cotype Rtt." (white, handwritten) (NMPC).

Identification (Fig. 9). Characters of the genus. Maximal length: $11.1 \mathrm{~mm}$; maximal width at base of elytra: $2.7 \mathrm{~mm}$. Male antennae as in Fig. 9a; antennomeres $\mathrm{V}-\mathrm{VI}$ and last male palpomere blackish. Head as in Fig. $9 \mathrm{~b}$ and $9 \mathrm{c}$; male frontal calli, in dorsal view, from the base progressively narrowing; in lateral view, the anterior margin of the crest obliquely sloping. Male maxillary palpomeres as in Fig. 9d. Pronotum as in Fig. 9e. Male anterior tibiae (Fig. 9f) with a wide and elongate depression on the inner side, with anterior margin abruptly curved. Male genitalia as in Fig. 9g.

Distribution (Fig. 10). Caspian Sea (Dvořák, 1989). Turkmenistan: Tedzhen (Reitter, 1906; Kaszab, 1951; MABC;
HNHM; MCNV); Kara-Kum (Dvořák, 1989). Uzbekistan. Bukhara (Kaszab, 1951); Bukhara, Karakum (HNHM).

\section{Rhampholyssa steveni (Fischer von Waldheim, 1824)}

Cerocoma adusta Steven in litteris (see Semenow, 1895: 517).

Cerocoma steveni Fischer von Waldheim, 1824: 227.

Rhampholyssa komarowi Reitter, 1889: 119.

Rhampholyssa steveni: Reitter, 1889: 119; Semenow, 1895, 517-518; Reitter, 1909: 102-103; Kaszab, 1951: 256-257, 270; Dvořák, 1989: 17.

Rhampholyssa steveni var. komarowi: Semenow, 1895: 519; Kaszab, 1951: 257, 270.

Rhampholyssa steveni var. intermedia Semenow, 1895: 518; Kaszab, 1951: 257, 270.

Rhampholyssa steveni var. pallida Semenow, 1895: 519; Kaszab, 1951: 257, 270.

Rhampholyssa steveni var. varentzowi Semenow, 1895: 518-519; Kaszab, 1951: 257, 270.

Rhampholyssa steveni var. plagicollis Reitter, 1909: 102-103; Kaszab, 1951: 257, 270.

Type locality. "Rossia meridionalis" (Fischer von Waldheim, 1824). The type localities of the various intraspecific forms are respectively: var. komarowi: "Afganistan" (Reitter, 1889); var. intermedia: "Margelan" (Semenow, 1895); var. pallida: "Kizilkum: ad fontem Dussebaj" (Semenow, 1895); var. varentzowi: "st. Michajlovskaja" (Semenow, 1895); var. plagicollis: "Uralsk" (Reitter, 1909).

Type material. The type of this species was not examined, as well as those of the var. intermedia, pallida and varentzowi, which are probably preserved in the St. Petersburg or Moscow Museums. We examined the following types of intraspecific forms: (a) Rhampholyssa steveni var. komarowi: holotype $\widehat{0}$ with the following labels: "Afganist. / Kuschke" (white, printed); "Monotypus 1888 / Rhampholyssa ô Komarowi / Reitter" (white, red printed and handwritten); "Rhampholyssa / komarowii / m." (white, handwritten, upturned); "Rhampholyssa ô / f. Komarowi Rtt. / det. dr Kaszab" (white, printed and handwritten) (HNHM). The last tarsomere of the hind left leg is missing. (b) Rhampholyssa steveni var. plagicollis Reitter, 1909. Holotype $\delta$ allotype $q$ paratype $\delta$ with the following labels: "Uralsk / Reitter" (white, printed); "Holotypus 1909 / Rhampholyssa Steveni / v. plagicollis ơ Reitter" (white, red printed and handwritten) (or "Allotypus ..."; "Paratypus ..."); "Rhampholyssa ơ ab. Plagicollis Rtt. / det. dr. Kaszab" (white, printed and handwritten) (HMNH).

Identification (Fig. 9). Maximal length: $10.1 \mathrm{~mm}$, maximal width at base of elytra: $2.4 \mathrm{~mm}$. Similar to $R$. antennata except for the following features: Black colouration of body variously extended but always only partial, usually body largely orange-brown; antennomeres and palpi brown-orange. Head as in Fig. 9i and 9j; male frontal calli, in dorsal view, angulate at base and then progressively narrowing anteriad; in lateral view, the anterior margin of the crest straight. Male antenna as in Fig. 9h; male palpomeres as in Fig. 9k. Pronotum as in Fig. 91; male protibia as in Fig. 9m. Male genitalia as in Fig. 9n.

Remarks. Females of $R$. steveni usually show a partial fusion of antennomeres III and IV. The body colouration of this species is very variable. Actually, the described intraspecific forms (intermedia, komarowi, pallida, plagicollis, varentzowi) represent variations in the black elytral spots or the presence of black colouration on other parts of body such as frontal calli or pronotum. One of these 
forms, komarowi, was described as a distinct species (Reitter, 1889), but considered as a variety in the following literature (Semenow, 1895; Kaszab, 1951). The only Afghanistan specimen examined, which is the type of the form komarowi, shows slight differences in the frontal calli, which have a less angulated base; this character is insufficient, at present, to distinguish komarowi as a subspecies.

Distribution (Fig. 10). Caspian Sea (Kaszab, 1951; Dvořák, 1989). Russia: S Russia (Motschulsky, 1873; HNHM; MNHN); E Siberia (Fischer von Waldheim, 1842: doubtful record, probably referrable to a region of Central Asia). Iran: Kashan: Abused-abad (Dvořák, 1996). Kazakhstan: SE Kazakhstan, 30 km S-SE Koktal village, Ily-river, Barakhudzyr (Nikolaev \& Kolov, 2005); SE Kazakhstan, 5 km S-SE Aydarly village, Ilyriver (Nikolaev \& Kolov, 2005); SE Kazakhstan, Ily river (HNHM); W Kazakhstan, Novaya Kazanka (Nikolaev \& Kolov, 2005); Uralsk (Reitter, 1909; Kaszab, 1951; NMPC; HNHM). Turkmenistan/Uzbekistan: Bukhara, Repetek (MABC; NMPC). Turkmenistan (Reichardt, 1934; Dvořák, 1989; HNHM; NMPC); Tekke (MNHN); Chorezmskaya obl. Kara Kum desert, 10 km SE Chiva (HNHM); Transcaspia, Ouzoun-Ada (MNHN); E Turkestan, Aulie, Farab (Kaszab, 1951; HNHM); Repetek (Semenow, 1895; NMPC); Tedzhen (NMPC); Takyr (MABC); Dargan Ata env. (SKC, MABC); Imambaba (NMPC). Uzbekistan: Margelan (Semenow, 1895); 20-30 km SE Kagan, Karaulbazar (SKC); Bukhara (Kaszab, 1951); Fergana (Kaszab, 1951). Kyrgyzstan: Kyrgyzstan (Dvořák, 1989); Kirgisensteppen (Kaszab, 1951). Tajikistan (Pripisnova, 1987). Afghanistan (Kaszab, 1951; NMPC; HNHM).

\section{Key to species}

1 Male antennomeres V-VI and last palpomere dark; base of frontal calli, in dorsal view, with progressively curved profile, the anterior portion, in lateral view, slightly inclined; male anterior tibiae in dorsal view with an inner wide depression. .................... R. antennata

- Antennomeres and palpi yellow-brown; base of frontal calli, in dorsal view, with more angulate profile, the anterior portion, in lateral view, straight; male anterior tibiae in dorsal view with an inner narrow depression. . . . . . . . R. steveni

\section{KEY TO THE GENERA OF THE TRIBE CEROCOMINI}

1 Protibiae with one apical spur. Elytra yellowish with or without black maculae, never metallic. . . . . . . . . . . 2

- Protibiae usually with two apical spurs (rarely one or both spurs absent). Elytra completely or partially metallic. ... . 3

2 Eight antennomeres. Male frons with a high longitudinal crest, which is profoundly concave laterally; eye major axis subequal to or only slightly longer than frontal crest height. Female antennomeres progressively widened, V-VII normally shaped, subtrapezoidal. Elytra uniformly yellow, at most only slightly darkened at apex. (Central Asia). . .

........................... Rhampholyssa

- Nine antennomeres. Male frons with a weak longitudinal crest which is only weakly concave laterally; eye major axis distinctly longer than frontal crest height. Female antennomeres V-VIII transverse and evidently wider than the previous ones. Elytra with a black macula at middle and a black apex. (Arabian Peninsula)............ Rhampholyssodes

3 Nine antennomeres. Male anterior tarsi usually modified. [From Spain and north-western Africa (Morocco) through Europe and Near East to Iran and Central Asia]. . Cerocoma

- Eleven antennomeres. Male anterior tarsi not modified. . . 4
4 Head, pronotum and abdomen metallic or rarely black, never yellow-orange. Male anterior tibiae simple or variously modified along the whole - or part of - length. (Sahara, Arabian Peninsula, Palestine, S Iran). . . . . . . . . . . ......................... Diaphorocera Head, pronotum at least in part, and abdomen yellow-orange. Male anterior tibiae simple or with a basal expansion. ....................... 5

5 Body brown-orange, with elytra entirely or only apically metallic green-violet. Male frontal calli slightly protruded in front, forming a low crest, but frons moderately depressed on sides. Male anterior tibiae with a small basal, external, pedunculate expansion; spiniform black setae at base of protibia and at apex of the profemur. Penis with two apical hooks, endophallus hook bidentate. (Iran, Iraq?, Arabia?). . . .......................... Anisarthrocera

- Body orange, but head orange or black, metathorax black and elytra completely metallic violet-green. Male frons with calli only a little raised, not protruded anteriad. Male anterior tibiae simple; no spiniform setae on anterior legs. Penis with single apical hook, endophallus hook unidentate. (N Somalia, S Kenya). . . . . . . . . Somalarthrocera gen. $\mathrm{n}$.

ACKNOWLEDGEMENTS. We wish to thank the following naturalists for permission to study the Meloidae preserved in their institutions or private collections and for their help: $\mathrm{M}$. Barclay, London (BMNH); C. Girard and L. Casset, Paris (MNHN); O. Merkl, Budapest (HNHM); J. Hájek, J. Jelínek and V. Švihla, Prague (NMPC); M. Bon and E. Ratti, Venezia (MCNV); S. Krejčík, Uničov, Czech Republic. We also thank S. Serri (Tehran, PPT) for her help with the field research and for information on Iranian localities. W. Hamza of the Al Aïn University kindly supported our research in the United Arab Emirates. Thanks to our Italian colleagues D. Avesani, G.M. Carpaneto, P. Cerretti and G. Nardi for the collection of the new Somalarthrocera species from Kenya. R. Poggi, Museo Civico di Storia Naturale "G. Doria", Genova, supplied us with old literature, P. Bombi helped us with maps, and A. Di Giulio (both at Roma Tre University) with other technical matters. This study was supported by grants from the University "Rome Tre", Department of Biology ("ex 60\%" and "Programmi di ricerca scientifica di rilevante interesse nazionale, $n$. 99C5271884-007") and from the Ministero dell'Istruzione, dell'Università e della Ricerca (coordinator M.A. Bologna, n. 2004057217). We wish also to acknowledge the financial support of the European Commission's Research Infrastructure Action via the "SYNTHESYS Project", thanks to which research in some European Museums was carried out by one of us (FT) (FR-TAF-44 and HU-TAF-288).

\section{REFERENCES}

Bologna M.A. 1990: Faunistica e zoogeografia dei Meloidae (Coleoptera) della Somalia. Biogeographia (n.s.) 14: 293-401.

Bologna M.A. 1991: Coleoptera Meloidae. Fauna d'Italia. XXVIII. Calderini, Bologna, xiv +541 pp.

Bologna M.A. \& Pinto J.D. 2001: Phylogenetic studies of the Meloidae (Coleoptera), with emphasis on the evolution of phoresy. Syst. Entomol. 26: 33-72.

Bologna M.A. \& Pinto J.D. 2002: The Old World genera of Meloidae (Coleoptera): a key and synopsis. J. Nat. Hist. 36: 2013-2102.

Bologna M.A. \& Turco F. 2007: The Meloidae (Coleoptera) of the United Arab Emirates with an updated Arabian checklist. Zootaxa 1625: 1-33. 
Bologna M.A., Fattorini S. \& Pinto J.D. 2001: Review of the primitive blister beetle genus Iselma with description of the first instar larva (Coleoptera: Tenebrionoidea: Meloidae). Afr. Entomol. 9: 105-129.

Bologna M.A., D’Inzillo B., Cervelli M., Oliverio M. \& Mariottini P. 2005: Molecular phylogenetic studies of the Mylabrini blister beetles (Coleoptera, Meloidae). Mol. Phylogenet. Evol. 37: 306-311.

Bologna M.A., Di Giulio A. \& Pitzalis M. 2008: Systematics and biogeography of the genus Actenodia (Coleoptera: Meloidae: Mylabrini). Syst. Entomol. 33: 319-360.

Cros A. 1939: Les Meloidae des possessions françaises de l'Afrique du Nord - étude biogéographique. Bull. Ann. Soc. Entomol. Belg. 79: 247-265.

Di Giulio A., Turco F. \& Bologna M.A. 2002: Larval morphology of the genus Cerocoma and phylogenetic implications (Coleoptera, Meloidae). Entomol. Fenn. 13: 105-112.

DvořÁK M. 1989: Tribus Cerocomini (Coleoptera, Meloidae, Meloinae). Keys for identification of insects No 8. Zprávy Čs. Spol. Entomol. (Suppl.), 20 pp. [in Czech].

DvoŘÁK M. 1996: Ergänzung zum Bestimmungschüssel der Tribus Cerocomini (Coleoptera: Meloidae). Klapalekiana 32: 159-162.

FAIRMAIRE L. 1882: Coléoptères recueillis par M.G. Révoil chez les Çomalis. In Révoil G.: Faune et Flore des pays Çomalis (Afrique orientale). Challanel Ainé, Paris, pp. 1-104.

Fischer von WaldheIm G. 1824: Entomographie de la Russie. Tome II. 1823. Entomographie de la Russie. Ouvrage dédié à sa Majesté l'Empereur Alexander I-er. Entomographia Imperii Rossici. Suae Caesareae Majestati Alexandro I dicata. Volumen II. Cum XL tabulis aeneis. 1823-1824. Augusti Semen Typographi Acad. Caes. Medico-chir. Excusa, Mosquae.

Fischer von WaLdheIM G. 1842: Catalogus Coleopterorum in Sibiria Orientali a Cel. Gregorio Silide Karelin collectorum. Moscou.

Kaszab Z. 1951: Revision der Cerocominen. Acta Biol. Acad. Sci. Hung. 2: 255-274.

Kaszab Z. 1968: Contribution à la faune de l'Iran, 8. Coléoptères Meloidae. Ann. Soc. Entomol. Fr. 4: 749-776.

Kaszab Z. 1983: Insects of Saudi Arabia - Coleoptera: Fam. Meloidae - A synopsis of the Arabian Meloidae. Fauna of Saudi Arabia 5. A. Fricker AG, Frick \& Karger Libri AG, Basle, pp. 144-204.

Kolbe H.J. 1897: Käfer und Netzflüger Ost-Afrikas. In Möbius K. (ed.): Deutsch-Ost-Afrika und der Nachbargebiete. Deutsch-Ost-Afrika 4. Reimer, Berlin, pp. 1-368.

KraAtz G. 1863: Revision der Cerocomiden-gruppe. Berl. Entomol. Z. 1863: 109-115.

Marseul S.A. DE 1872: Description d'espèces nouvelles. $L$ 'Abeille 8: 413-420.

Mirzayans H. 1970: Contribution à la connaisance de la faune des Clérides et Méloides de l'Iran. Entomol. Phytopathol. Appl. 29: 25-37.

Modarres Awal M. 1997: List of Agricultural Pests and their Natural Enemies in Iran. Ferdowsi University of Mashhad, Publication n. 147. Ferdowsi University Press, Mashhad.

MotschUlsKy V. vON 1873: Enumération des nouvelles espèces de Coléoptères rapportés de ses voyages. Bull. Soc. Imper. Nat. Moscou 45: 23-53.

NiKolaev G.V. \& Kolov S.V. 2005: Blister Beetles of Kazakhstan. Kazakh University publishing, Almaty.

Pinto J.D. \& Bologna M.A. 1999: The New World genera of Meloidae (Coleoptera): a key and synopsis. J. Nat. Hist. 33: 569-619.
Pinto J.D., Bologna M.A. \& Bouseman J.K. 1996: First-instar larvae, courtship and oviposition in Eletica: amending the definition of the Meloidae (Coleoptera: Tenebrionidae). Syst. Entomol. 21: 63-74.

PriPISNOVA M.G. 1987: Fauna and Ecology of the Meloid Beetles (Coleoptera, Meloidae) of Tadzhik SSR. Entomol. Obozr. 66: $555-571$.

ReICHARDt A.N. 1934: Bestimmungstabelle und Liste der Plasterkafer Turkmeniens. Trudy Akad. Nauk Turkmen. SSR 6: 205-239.

ReITTER E. 1889: Coleopterologische Ergebnisse der in Jahre 1886 und 1887 in Transcaspien von Dr. G. Radde, A. Weter, A. Konchin, augefürther Expedition. Verh. Naturforsch. Ver. Brünn 27[1888]: 95-133.

ReitTer E. 1906: Neue Coleopteren aus der Palearktischen Fauna. Wien. Entomol. Z. 25: 31-37.

ReitTer E. 1909: Neun neue Coleopterenarten und Varietäten aus der paläarktischen Fauna. Wien. Entomol. Z. 27: 99-103.

Semenow A. 1895: De genere Rhampholyssa Krtz. Horae Soc. Entomol. Ross. 29: 515-519.

Swofford D.L. 2002: PAUP*. Phylogenetic Analysis Using Parsimony (*and Other Methods). Version 4. Sinauer Associates, Sunderland, Massachusetts.

Turco F. \& Bologna M.A. 2007: Revision of the genus Diaphorocera Heyden, 1863 (Coleoptera, Meloidae, Cerocomini). Contrib. Zool. 76: 63-85.

Turco F., Di Giulio A. \& Bologna M.A. 2003: Sexual and cleaning behaviour and related morphology in the genus Cerocoma (Coleoptera: Meloidae). J. Insect Behav. 16: 257-278.

Turco F., Di Giulio A. \& Bologna M.A. 2006: The first larval description in the genus Diaphorocera Heyden (Coleoptera: Meloidae: Cerocomini): D. chrysoprasis Fairmaire. Zootaxa 1295: 29-39.

Received July 2, 2007; revised and accepted December 11, 2007

APPENDIX 1. Unordered and unweighted characters used in the phylogenetic analysis.

Head

1. Number of antennomeres: $11(0)$, less than $11(1)$.

2. Pointed and curled expansion on ventral side of antennomere III: absent (0), present (1).

3. Shape of frontal calli: absent (0), large and slightly protruding (1), narrow and evidently protruding, forming a more or less elevated keel (2).

4. Shape of labrum, in middle with: a longitudinal depression (0), a distinct longitudinal smooth area, more or less raised (1).

5. Maxillary stipites: short (0), elongate (1).

6. Width of palpomere II compared to III: subequal (0), smaller (1), larger (2).

7. Palpomere IV length compared to own width: at least twice (0), less than twice (1).

8. Shape of palpomere IV apex: convex (0), with an evident hollow (1).

9. Shape of antennomere I: simple, not flattened (0), flattened and enlarged (1).

10. Shape of antennomere VII: not evidently enlarged (0), evidently enlarged (1).

Thorax

11. Depression on the inner side of the distal half of male anterior tibiae, in dorsal view: absent (0), present (1).

12. Number of spurs on anterior tibiae: $2(0), 1$ (1). 
13. Colour of elytra: at least partially metallic (0), not metallic (1).

14. Shape of pronotum: subsquare (maximum length/maximum width $<1.5)(0)$, elongate $(\mathrm{ml} / \mathrm{mw}=1.5)(1)$.

\section{Abdomen}

15. Shape of parameres, on ventral side: not or moderately sinuate (0), evidently sinuate (1).

16. Maximum length of parameres compared to maximum length of phallobase: subequal (0); distinctly longer (1).

17. Number of penis hooks: 2 (0), 1 (1).

18. Position of penis distal hook: subapical (0), apical (1).

19. Shape of penis distal hook: oblique (0), curved (1).

20. Penis distal hook: slightly protruding (0), distinctly protruding (1).

21. Endophallic hooks: unidentate (0), bidentate (1).
Appendix 2. Data matrix for the 13 cerocomine species used in the phylogenetic analysis.

\begin{tabular}{|c|c|c|}
\hline & & 111111111122 \\
\hline & 123456789 & 012345678901 \\
\hline Lytta vesicatoria & 0000000000 & 0000000000000 \\
\hline Pyrota akhurstiana & 0000000000 & 000010001100 \\
\hline Cerocoma schaefferi & 1010000001 & 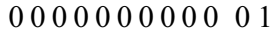 \\
\hline C. schreberi & 101000001 & 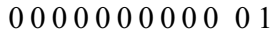 \\
\hline C. scovitzi & 101000001 & 000000000000001 \\
\hline C. vahli & 101 & 0000001 \\
\hline Diaphorocera hemprichi & 001110000 & 100000000000001 \\
\hline D. obscuritarsis & 001110000 & 10000000000001 \\
\hline D. promelaena & 0000 & 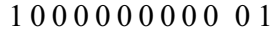 \\
\hline Somalarthrocera savanicola & 001112000 & 100000111110 \\
\hline S. semirufa & 001112000 & 100000111110 \\
\hline Anisarthrocera batesi & 002011100 & 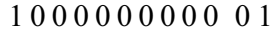 \\
\hline Rhampholyssa antennata & 102011111 & 0111111001111 \\
\hline R. steveni & 102011111 & 011111001111 \\
\hline Rhampholyssodes pitcheri & 112010101 & 011111000000001 \\
\hline
\end{tabular}

